\title{
obituary
}

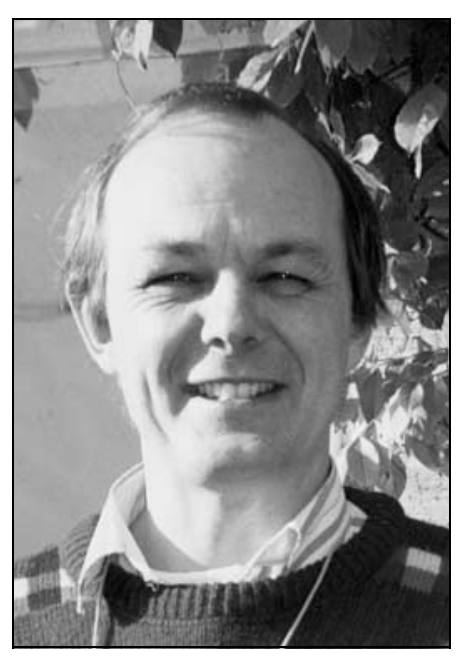

\section{James William Birch}

Consultant Psychiatrist North General Hospital, Tyne \& Wear

Dr Birch's life was cut short at 53 in a tragic car accident in October 2000.
Jim was born in 1947 at Oakham, in Rutland. He trained at Charing Cross Hospital and graduated MBBS (London) in 1970. After taking up a number of posts in psychiatry - adolescent, forensic and adult - he started training to be a psychotherapist. He gained the DPM (England) in 1973 and the MRCPsych and the Dip Psychother (Leeds) in 1976

Jim then moved to Carmarthen in West Wales where he worked at St David's Hospital, taking a course in Welsh and starting to show an interest, which was to be developed later, in family therapy. He subsequently moved to Sussex but a few years later moved back to Wales and then spent 2 years in Torquay as a clinical assistant. In January 1985 the family emigrated to Australia where Jim worked as a family therapist at the Bouverie Family Therapy Centre in Melbourne. Another spell followed at the Dulwich Family Therapy Centre in Adelaide before his return to the UK in 1988 to the Newcastle area.

This was a man who liked variety, enjoyed travel and was ever enthusiastic about some project or other He had a childlike interest in life, which never waned and he was innately curious with a practical bent. He had quite an aversion to dogma or rhetoric and was certainly not of the bow tie or monocle brigade. He was a staunch supporter of the Green Party and had even stood for local election.

He will be remembered for many things, not least of which were his love and respect for children; he took a genuine interest in them as equals, joining in their games or interests, from flying a kite to a computer conundrum. He was friendly, outgoing, not people-shy, interested in others: excellent characteristics for a family therapist.

He read widely and liked to know about alternative philosophies of life. He was particularly interested in the meditation aspect of Buddhism. He is survived by his wife Maggie and children Emma, Dylan, Kean and Rosamonde.

Adel and Kamelia El-Sobky

\section{reading about}

\section{The child and young person with a learning disability: a guide to self-help resources and information}

Children with learning disabilities require constant support in order to live an ordinary life with their families. It is important that parents receive clear and appropriate information and that the child can gain access to materials that explain and allow a better understanding of his or her special problems. Today parents and individuals themselves have chosen the term learning disability in order to convey information about the disability, this term will be used throughout. We have looked at many resources available from organisations and the internet and outline a few available texts.

\section{Children with learning disabilities and their families}

The Tavistock Clinic has published a series of books designed to help parents to understand and anticipate the needs of their children. The series titled Understanding ... starts from the newborn baby and continues well into adolescence.
The series includes the title Understanding Your Handicapped Child (Sinason, 1993). This contains factual information about disability and vignettes from the therapist's own practice. It examines the prac tical as well as emotional issues that are involved in the care of a child with a learning disability and gives some description of the roles of the different professionals who are likely to be involved.

The Mental Health Foundation has also considered in three of its publications (Learning Difficulties and the Family) the problems that confront parents. The first publication deals with problems arising at the moment when parents realise that their child has been diagnosed with a learning disability (The Young Child with a Learning Disability); the second deals with the impact of a child with a severe disability on the family and the need for constant support and supervision (The Teenager with Severe Learning Difficulty). The third considers the questions that arise about the child's independence and how to allow an adult relationship to develop, aiming at individuation and separation (Leaving Home, Moving on)

In the UK the Royal College of PsychiaGrowing Up (Tufnell, 1999), containing 36 trists published Mental Health and factsheets that have information about the emotional and psychological problems of children and young persons. The two that give information on learning disabilities, autism and Asperger's syndrome are addressed to parents, carers or teachers. Similar information is available from the American Psychiatric Association and associated agencies. The American National Institutes of Health (http:// www.nih.gov) also offer information for parents whose children have learning disabilities or in addition have attentiondeficit hyperactivity disorder (ADHD). Jessica Kingsley Publishers produce a range of books on topics such as how to cope with a child with a challenging behaviour, how to organise an appropriate environment for a child with special needs and develop the child's skills and abilities in everyday activities. Information for parents on education and special needs can be found in guides published by the Department of Education (http:// www.DFEE.gov.uk). Advice to young people with disabilities themselves is also available.

Books Beyond Words have been designed by Professor Sheila Hollins and others (St George's Department of Psychiatry of Disability) for a person with a learning disability to deal with situations 